\title{
LA GRAMATICA DE LOS CASOS DEL ESPAÑOL*
}

\author{
Jack L. Wilson
}

\begin{abstract}
This article begins with a rapid taxonomic overview of Case Grammar as applied to Spanish. The second part illustrates insights provided by the theory in the interpretation of certain phenomena, such as the different uses of 'se'. The Royal Spanish Academy is criticised for its interpretation of the so-called 'passive with se'.
\end{abstract}

de la publicación en 1957 de Estructuse Noam Chomsky, las teorías linmás importantes han exigido no solae describan los hechos y fenómenos aje, como tradicionalmente se había hetambién que se expliquen. Con esa finaomsky introdujo cambios básicos en su en 1965 salió la obra Aspectos de la teosintaxis, que ha servido de modelo para ipulos de la Gramática generativa hasta el

la misma finalidad se publicó en 1970 la Wallace Chafe El significado y la estructuenguaje $y$, a fines de la década de los seprincipios del setenta, se publicaron varios de James McCawley, George Lakoff y no los cuales se dio inicio a un nuevo movilingü ístico, el de la Semántica generativa. inmediato se dividieron en dos bandos los que se habían mantenido al corriente iscusiones lingü ísticas de los últimos años, a la aparente incompatibilidad que había dos teorías. En 1968 Charles Fillmore el trabajo El caso para el caso, en el que dar cuenta de fenómenos semánticos cían de difícil explicación en el modelo por Chomsky, pero siempre como parteoría.

ore aceptó la tesis de Chomsky según la sintaxis debe ser considerada central en a de lenguaje, pero los nuevos adeptos de que ya se identificaba como la Gramácasos, pretendieron introducir modifica-

agradecer la colaboración del doctor Alfonso Martín en la revisión del estilo de este trabajo, no por las ideas que ha aportado. ciones sustanciales aceptando los lineamientos de los seguidores de la Semántica generativa. Chomsky, en el artículo Estructura profunda, estructura superficial e interpretación semántica, demostró para la satisfacción de la mayoría de los lingüistas que la Semántica generativa no es, realmente, una alternativa a la Gramática generativa, sino una simple variante. El presente artículo está escrito con este espíritu.

Partimos de la premisa de que el universo conceptual del hombre está inicialmente dividido en dos grandes áreas: por un lado, hay cosas concretas y conceptos reificados, $y$, por otro lado, hay estados, procesos y acciones que se pueden manifestar de diferentes maneras $y$ en diferentes combinaciones. Aun cuando hay otras áreas conceptuales, la Gramática de casos pretende dar cuenta específicamente de las relaciones semánticas que existen entre estas dos.

Se enfoca la oración como un conjunto de una o más proposiciones lógicas concatenadas que sufren modificaciones de distinta indole. Puesto que las oraciones complejas no son más que el resultado de concatenaciones de proposiciones simples, éstas son el objeto del análisis. Fillmore define la oración simple, que contiene una sola proposición, así:

$$
\mathrm{O} \rightarrow \mathrm{M}+\mathrm{P}
$$

donde $\mathrm{O}=$ Oración, $\mathrm{M}=$ Modalidad y $\mathrm{P}=$ Proposición.

A la modalidad pertenece todo aquello que afecta la oración en su totalidad, por ejemplo tiempo, aspecto y modo, modificaciones sentenciales tales como la topicalización y todo lo que esté im- 
plícito en el verbo, como, por ejemplo, son los casos facultativos. Se ven ejemplos de casos facultativos en las siguientes oraciones:

\section{Tengo cien colones en el bo/sillo.}

\section{El hombre le compró un helado a su hijo (= para su hijo).}

Toda oración en español admite ubicarse en el espacio, pero sólo un número limitado de verbos implican o exigen la manifestación explícita de una relación locativa. En el caso de 2, el verbo 'comprar' implica un comprador y un vendedor, pero no implica 'para alguien'. La especificación de relaciones no implicadas por el verbo es una de las funciones de la modalidad de la oración, si bien los casos de la modalidad, a su vez, tienen un origen proposicional.

Toda proposición consta de dos partes: un operador lógico y un mínimo de uno y hasta un máximo de tres variables lógicas, que podemos llamar 'argumentos'. Rompiendo con la terminología tradicional, a los operadores (que pueden incluir lo que tradicionalmente se ha designado como 'verbos, adjetivos, cuantificadores', y, en algunos casos, 'sustantivos') se les llama 'verbos' y a las variables se les llama 'sustantivos', aun cuando en algunos casos están lexicalizados en el verbo. EI operador, o verbo, manifiesta, de manera inherente o derivada, un estado, un proceso, una acción o una acción-proceso, e implica relaciones semánticas con sus argumentos, o sustantivos.

La relación semántica que existe entre un sustantivo y un verbo se llama 'relación casual', o 'relación de caso'. La relación semántica del sustantivo es variable, pues puede manifestar las siguientes relaciones: básica, experientiva, benefactiva, locativa o la relación de un objeto especificado como objeto en un estado $u$ objeto involucrado en un proceso. En el presente trabajo se darán ejemplos de estas relaciones.

Hay procedimientos para determinar si una oración simple es de estado, de proceso o de acción. Construcciones de proceso o de acción contestan a la pregunta '¿Qué pasó?'; no asi las construcciones de estado. Las construcciones de proceso contestan a la pregunta '¿Qué pasó a_—?', las construcciones de acción contestan a la pregunta '¿Qué hizo __ ?' y las construcciones de acción-proceso contestan a todas las preguntas.

\section{La relación básica}

Los verbos básicos implican un objeto en estado o un objeto involucrado en un cambio estado en proposiciones de un solo argument $\mathrm{Si}$ hay dos argumentos, el segundo tiene manifestar una relación agentiva.

\section{Verbos básicos de estado [ $\left[0_{\mathrm{e}}\right]$}

(La raya horizontal del simbolismo indica que el v bo acepta los argumentos que aparecen a la derech

El verbo de esta categoría implica que hay objeto semántico en un estado ( [ $\left.0_{\mathrm{e}}\right]$ ) puede manifestarse como una cópula más adjet vo o sustantivo, o como un verbo completable ca un sustantivo. Por ejemplo:

\section{El verano es seco.}

4. El hombre es hábil.

5. El elefante está muerto.

6. Goliat era (un) gigante.

7. Ese hombre es un payaso.

8. El gobierno vive endeudado.

9. Las papas pesan cinco kilos

10. El libro costó cien colones.

Cabe señalar que las cópulas 'ser' y 'estar' sc formas superficiales que desempeñan funcion: gramaticales pero carecen por completo de conti nido lexicosemántico. Son portadores de informe ción sobre tiempo $y$ aspecto y muestran la co cordancia que usualmente se asocia con forme verbales. 'Ser' y 'estar', así como 'vivir', que si nifica en este ejemplo 'estar siempre', señalan a gunas clases de estado que pueden caracteriz un determinado objeto. Sobre esto se hablará m adelante.

Lo que lleva la fuerza predicativa en oracion como 3 a 8 no es la cópula, sino el adjetivo o su tantivo que le sigue. Varios lingüistas han deme trado que la principal diferencia entre verbos $y$ a jetivos es formal: los verbos se conjugan, los adj tivos no, y los dos muestran diferentes clases concordancias con un antecedente nominal. embargo, su comportamiento sintáctico, a difere 
su comportamiento morfológico, es igual. Lakoff en el artículo Stative verbs and ves in English, ha enumerado una larga serie uebas, muchas de las cuales son también les al español, para demostrar que los verlos adjetivos son simples variantes de una categoría sintáctica. De las pruebas de aplicaré dos al español.

ados los verbos del español se pueden dividos categorías en cuanto a si admiten o no en construcciones imperativas:

iPinte la casa! * iNecesite el lápiz! (El asterisco significa que la oración no es gramatical).

ilHáblele al mecánico! * iQuiera un pedazo de torta!

igual manera se pueden dividir los adjeti-

iSea bueno! * iSea alto!

iEstáte quieto! * iEstáte cansado!

Eractamente estas mismas formas son las que estar, o no pueden estar, en construcciones "Convencí al hombre de que (no) + subjunti'o 'Convencí al hombre a (no)

Convencí al hombre a que pintara la casa. Convenci al hombre a pintar la casa.

* Convencí al hombre de que necesitara el lápiz.

*Convencí al hombre a necesitar el lápiz.

Convencí al hombre de que le hablara al mecánico.

Convencí al hombre a hablarle al mecánico.

* Convencí al hombre de que quisiera un pedazo de torta.

*Convencí al hombre a querer un pedazo de torta.

Convencí al niño de que fuera bueno. Convencí al niño a ser bueno.

*Convencí al hombre de que fuera alto. *Convencí al hombre a ser al to.
21. Convencí al niño de que se estuviera quieto. Convencí al niño a estarse quieto.

22. * Convencí al hombre de que se estuviera cansado.

*Convencí al hombre a estarse cansado.

Las mismas pruebas son aplicables a los sustantivos, o sintagmas nominales, cuando van precedidos de una cópula:

23. iNo seas payaso!

Convencí al hombre de que no fuera payaso. Convencí al hombre a no ser payaso.

24. * iNo seas gigante!

*Convencí al hombre de que no fuera gigante.

*Convencí al hombre a no ser gigante.

Para dar cuenta del fenómeno, tratándose de verbos y adjetivos, Lakoff postuló un rasgo binario [ \pm estativo]. Los verbos y adjetivos que no admiten el imperativo se marcan con el rasgo sintáctico [ - estativo] y los que lo admiten se marcan con el rasgo sintáctico [+ estativo]. Parece más viable la postulación de un rasgo semántico, antes que un rasgo sintáctico, el rasgo [ \pm controlable]. Para que pueda haber una construcción imperativa, el sujeto tiene que tener la capacidad de controlar la situación pedida. En situaciones sobrenaturales o donde hay una autoridad, la persona, o el ser, que da la orden puede controlar la situación. En el primer caso, el imperativo sólo puede ser usado en una construcción que representa una acción; en el otro caso no se presenta esa limitación. Esto es igualmente cierto para verbos y para la cópula seguida de un sustantivo o sintagma nominal, si bien en este último caso es de esperarse que sean menores las situaciones en que el sujeto de la oración esté en condiciones de controlar su situación.

Los números 9 y 10 representan una clase de predicados (operadores, o los que estamos llamando 'verbos'), en los cuales la forma verbal y su complemento funcionan con una sola unidad. La mayoría de los predicados de esta clase consisten en un verbo seguido de un sintagma nominal que expresa una cantidad. Con verbos de esta clase no cabe la transformación pasiva:

\section{5. *Cinco kilos son pesados por las papas.}

26. *Cien colones fueron costados por el libro. 
Verbos básicos de proceso<smiles>[Hg]</smiles>

Los verbos de esta categoría enfocan el cambio de estado de un objeto: el inicio del cambio, el fin del cambio o una extensión entre el inicio y el fin. En español hay tres clases de verbos clásicos de proceso:

A. En algunas construcciones que tratan de condiciones atmosféricas, se usa el proyecto de proceso 'hacer':

27. Hizo frío.

28. Hace calor.

29. Hace mucho viento.

Si bien es posible hacer la pregunta '¿qué hizo'?, que antes se mencionó como la prueba para determinar los verbos de acción, se ve que este 'hacer' no es el mismo, pues no admite el imperativo, ni siquiera en una situación sobrenatural. El mismo Dios probablemente no diría '* ihaz frío!' sino 'ique se haga frío!'.

B. En algunos casos el objeto está lexicalizado en el verbo mismo:

30. Está nevando (que significa que la nieve está cayendo).

31. Está lloviendo (que significa que está cayendo la lluvia).

En ambos casos, A y B, es posible hacer la pregunta 'iqué pasó?' o 'iqué pasa?! En ningún caso es posible el imperativo. En el caso B, el mismo Dios probablemente diría 'ique llueva!', o sea, usaría el imperativo indirecto. Otros ejemplos son:

\section{Amaneció.}

33. Anocheció.

C. La mayoría de los verbos básicos de proceso en español enfocan el cambio de estado de un objeto que se manifiesta como un sustantivo presente en la oración. En estos casos cabe la pregunta '¿qué le pasó a__?', pero no cabe la pregunta '¿qué hizo__?'. El sujeto del verbo no controla el contenido del verbo y por lo tanto cabe el imperativo si lo pronuncia un ser sobrenatural o per de tanta autoridad que él mismo puede que el proceso se lleve a cabo:

34. La ventana se quebró.

¿Qué le pasó a la ventana?

* ¿Qué hizo la ventana?

35. El elefante se murió.

36. La puerta se abrió.

37. La ropa se secó.

38. *Ventana, iquiébrese!

39. * iMuérase!

En 38 y 39 la fuerza predicativa no depende sujeto del imperativo sino de la persona, o ser, lo pronuncia. El significado es 'Voy a hacer + subjuntivo'. Así, por ejemplo, Herodes pudo cirle a Jesús ' iMuera!' con el significado de a hacer que muera!. Los imperativos con verbe proceso no son, pues, verdaderos imperativos el resultado de una elípsis.

Verbos básicos de acción A]

Los verbos de acción simple son sólo supe cialmente intransitivos. En el nivel semánt además de tener un agente también hay un a to. Los verbos que son superficialmente intra tivos se subdividen en dos tipos:

A. El objeto puede estar lexicalizado en el bo:

40. La multitud cantaba. El objeto 'canto' lexicalizado en el verbo.

41. Los niños bailaban. El objeto 'baile' lexicalizado en el verbo.

Con verbos de esta clase es posible traer el co plemento a la superficie:

42. La multitud cantaba el Himno Nacio

43. Los niños bailaban El Torito. 
B. El agente, que manifiesta el sujeto de la oración, puede ser correferencial con el objeto:

44. El hombre corrió.

En esta oración, 'el hombre' hizo algo $y$, por lo tanto, es el agente, pero, al mismo tiempo, es el objeto que está en movimiento.

45. El hombre trabajó duro.

De la misma manera, 'el hombre' hizo algo, función del agente, pero, al mismo tiempo, fue el objeto del trabajo. El agente es la causa de una acción y el objeto es el recipiente de la acción o sobre lo que recae la acción. En este caso, la acción recayó sobre el mismo hombre de modo que él es, a la vez, agente y objeto.

\section{Verbos básicos de acción-proceso [__ A, O]}

En todas las categorías anteriores la proposición manifestaba en la superficie un solo argumento, pero las acciones y los procesos pueden combinarse en proposiciones que contienen dos, o tres, argumentos. Existe en español una división de verbos clásicos de acción en acción simple (en A y B arriba en que el proceso es implícito pero no explícito) y en acción-proceso donde el proceso tiene una manifestación en la oración. Los verbos de acción-proceso explícito, a la vez, se subdividen en dos subclases.

A. Como resultado de la acción especificada por el verbo surge algo que no estaba antes, o un objeto cambia de forma o de posición:

46. El jugador quebró la ventana.

47. El conserje abrió la puerta.

48. El vecino construyó una casa.

49. Cervantes escribió El Quijote.

50. Goya pintó desnudas.

B. Como resultado de la acción especificada por el verbo un objeto sufre un cambio, pero este cambio no es de forma:

51. Cervantes publicó El Quijote.
52. El portero tocó el timbre.

53. La mujer secó la ropa.

Las oraciones 49 y 50 pueden compararse con

54. Goya (no) pintó las desnudas, y

55. El vecino pintó la casa.

si bien 54 y 55 son manifestaciones de una relación locativa y no de la subclase básica de acción-proceso.

\section{La relación experientiva}

Los verbos experientivos son aquellos en que un objeto es el estímulo de una emoción o sensación, o especifica el contenido de un conocimiento, y hay un ser animado que experimenta la emoción, la sensación o el conocimiento. La relación de este ser es de un 'experientivo'.

Verbos experientivos de estado $\left.E_{e}, 0\right]$

Hay un ser animado en un estado que experimenta una emoción, una sensación o un conocimiento:

\section{El muchacho quería un helado.}

En esta oración 'el muchacho' no hizo nada ni nada le pasó. De hecho no pasó nada. 'El muchacho' estaba en un estado y experimentaba un deseo. El contenido del deseo era 'un helado'. 'El muchacho', pues, manifiesta el caso experientivo en un estado $\left(E_{e}\right)$ y 'el helado' manifiesta el caso objetivo (0).

\section{Al muchacho le gustaba el helado.}

Esta oración es muy parecida a la anterior. 'El muchacho' estaba en un estado y experimentaba una sensación ('gusto'). El objeto del gusto (lo que provocaba la sensación) era 'el helado'. La diferencia entre esta oración y la anterior es meramente formal: en la 56 'el muchacho' es el sujeto de la oración, y en la 57 'el helado' es el sujeto. Las relaciones semánticas en cada oración son las mismas. Ejemplos como estos son un indicio de que la selección del sujeto en español es arbitraria y no depende de criterios semánticos. 


\section{Roberto sabe francés.}

La oración contiene una descripción de Roberto. Roberto no hace nada ni nada le pasa, como tampoco pasa nada. 'Roberto' está en un estado: tiene un conocimiento. El contenido del conocimiento es 'el francés'. 'Roberto', pues, manifiesta el caso experientivo en un estado y 'el francés' manifiesta el caso objetivo.

Otros ejemplos son:

59. El niño ama a su mamá.

60. El paisaje es agradable.

61. El profesor es aburrido.

62. No me importa el dinero.

63. No oigo nada.

En 60 y 61 el sustantivo manifiesto es el contenido de una sensación. Cuando hay una sensación, tiene que haber un ser animado que la sienta. En los dos ejemplos citados no se hace explícito quién experimenta la sensación, pero la categoría permanece implícita en la mente, tanto de la persona que pronuncia la oración como de la persona que la oye. En español existen, pues, no sólo relaciones semánticas explícitas sino también relaciones semánticas implícitas.

Verbos experientivos de proceso $E, 0]$

Hay un ser animado que sufre un cambio de estado emocional de percepción o de conocimientos, y un objeto responsable (sin que medie la noción de voluntad) por este cambio o es el contenido del cambio:

\section{La oscuridad asustó a los niños.}

'Los niños' sufrieron un cambio, de no asustados a asustados. 'La oscuridad' causó el cambio pero no fue agente porque no 'hizo' nada. Antes bien, la fuerza de la oración es que 'los niños se asustaron por causa de la oscuridad'. 'Los niños' manifiesta el caso experientivo de proceso y "la oscuridad', el caso objetivo.

65. Sentí el temblor.
El 'yo' experimentó una sensación, la cual fue provocada por 'el temblor'. Otros ejemplos son:

66. El paciente sufrió un trastorno digestivo.

67. Ayer me pasó algo extraño.

68. Supe la verdad del asunto.

Verbos experientivos de acción [__ A, E]

En estos casos hay un ser animado que experimenta una emoción, una sensación o un conocimiento, y un agente que, controlando la acción, provoca la situación. En estos casos, el agente es también el objeto de la situación experimentada.

\section{El monstruo asùstó a los niños.}

Fuera del contexto, esta oración es ambigua. La oración es representativa de la categoría de un verbo experientivo de acción si el monstruo asustó a los niños al propio. En ese caso, 'el monstruo' es a la vez agente y objeto. Si el monstruo no asustó a los niños al propio, la oración significa que los niños se asustaron al ver al monstruo' y la oración es paralela a 64 y es otro ejemplo de un verbo experientivo de proceso. Otro ejemplo parecido es

70. El payaso divirtió al público.

Con verbos de esta clase el objeto semántico puede estar lexicalizado en el verbo, como en los siguientes ejemplos:

71. El ladrón mintió a la policía.

Esta oración equivale a 'El ladrón dijo una mentira a la policía'. 'El ladrón' es la fuente activa de la comunicación (agente), 'la policía' recibe la comunicación (experientivo), y 'mentira' es el contenido de la comunicación (objeto). Otros ejemplos de objetos lexicalizados en el verbo son:

72. El muezín llamó (hizo un llamado) a los fieles.

73. La anciana consultó (hizo una consulta) al médico.

74. Pastora atormentó a los sandinistas.

75. La mamá de Mafalda le complació. 


\section{El OIJ interrogó al sospechoso.}

En todos los casos de verbos experientivos de amioion hay un objeto encubierto en la superficie.

\section{Werbos experimentivos de acción-proceso $A, E, O]$}

Con verbos de este tipo hay tres argumentos: un agente que hace la acción, un ser animado experimenta una emoción, sensación o conociento, $y$ un objeto patente que es el contenido. frecuencia el experimentivo queda sin espeificar en la superficie; sin embargo, siempre está nplícito en la oración.

El ejecutivo dictó la minuta a la secretaria.

El guía mostró la ciudad a los turistas.

El ladrón dijo una mentira a la policía.

El profesor enseñó Química a los estudiantes.

En 80 es posible elidir 'Química' pero queda en in mente que el profesor enseñó 'algo' a los estuflantes.

Nos avisaron que el avión llegaba tarde.

En 81 el contenido de la comunicación es una mación entera que funge como sintagma nominal.

22 Jesús Ilamó 'Pedro' a Simón.

43. Roberto escribió una nota a su novia.

\section{Werbos benefactivos}

Los verbos benefactivos implican un objeto que Escá en un estado de ser poseído o que está involuwado en un proceso (a menudo está cambiando de mano en una transacción), y un posesor en un eszado o el ganador o el perdedor en un proceso a una acción.

Werbos benefactivos de estado $\left[\_\mathrm{B}_{\mathrm{e}}, \mathrm{O}\right]$

En estos casos hay una cosa poseída (el objeto) un posesor (el benefactivo), si bien éste puede ver posesor potencial.
84. Ese hombre tiene un Mercedes.

85. Vesco posee muchos millones de dólares.

86. Ese libro me pertenece.

87. Ese malvado merece una golpiza.

88. Al soldado le fal tó valor.

89. A los ambiciosos les sobran oportunidades.

90. Necesito un lápiz.

Verbos benefactivos de proceso $[\ldots B, 0]$

Hay un cambio de estado de un objeto y un ganador o un perdedor explícito en la oración. El sujeto de la oración no 'hizo' nada, sino que algo le pasó.

91. Juan Carlos heredó el trono de España.

92. El minero perdió la veta.

93. Matute encontró un libro.

94. Juan Gómez ganó el premio.

95. Los empleados del banco se sacaron la lotería

Verbos benefactivos de acción A, B]

Las oraciones de este tipo manifiestan de manera explícita dos argumentos: el caso agentivo y el caso benefactivo. El caso objetivo está lexicalizado en el verbo.

96. El ladrón sobornó al policía.

'El ladrón' '(agente)' dio (o hizo) un soborno '(objeto)' 'al policía' (benefactivo). El objeto está lexicalizado en el verbo: 'sobornar'.

97. El médico ayudó (dio ayuda) al paciente.

98. El niño acariciaba a su perro.

99. El abogado defendía a (hacía la defensa de) su cliente.

100. El maestro alabó a su discípulo. 
101. El novio besó a la novia (le dio un beso).

Verbos benefactivos de acción-proceso

$\left[\_\mathrm{A}, \mathrm{B}, \mathrm{O}\right]$

Hay un agente que activamente hace, o hizo, algo, un benefactivo que recibió o perdió algo, y un objeto explícito (o implícito) que es el contenido de la transacción. El benefactivo puede elidirse en la oración pero permanece como categoría implícita.

102. El gitano le vendió el caballo al campesino.

103. El campesino le compró el caballo al gitano.

104. El estudiante devolvió el libro a la biblioteca.

105. Todos dimos dinero a la Cruz Roja.

106. El hombre pagó (a alguien) todas sus deudas.

\section{Présteme mil colones.}

En los casos como 105, el objeto puede ser suprimido en la superficie pero queda implícito en la oración.

Es evidente que las oraciones 102 y 103 significan básicamente la misma cosa. En ambas oraciones 'el gitano' perdió algo, 'el campesino' ganó algo y 'el caballo' fue el que cambió de mano. Pero en 102 se hace énfasis en lo que hizo el gitano, $y$ en 103 se hace énfasis en lo que hizo el campesino. Por lo tanto, en 102 'el gitano' manifiesta el caso agentivo y 'el campesino' manifiesta el caso benefactivo, mientras que en 103 los papeles están invertidos.

\section{Verbos locativos}

Con los verbos locativos hay siempre un objeto que está en un lugar o que está cambiando de lugar, y en este úl timo caso puede haber un agente responsable del cambio de lugar.

\section{Verbos locativos de estado $\left[\_\mathrm{O}_{\mathrm{e}}, \mathrm{L}\right]$}

Hay tres subcategorías de verbos locativos de estado en español: el operador consta de 'estar' seguido de una preposición, consta de una forma verbal en la superficie y el objeto es el sujeto de la oración o consta de una forma verbal en la superficie y el locativo es el sujeto de la oración.
A. La cópula estar más preposición.

108. El mantel está sobre la mesa.

109. El granero está detrás de la casa.

110. San José está en Costa Rica.

En todos estos casos lo que lleva la fuerza ve bal es la cópula más la preposición. En lo siguien tes ejemplos, hay una fusión entre la preposición y la expresión locativa:

111. La mesa está aquí = La mesa está en este gar.

112. El perro está afuera $=$ El perro está fuera este lugar.

B. La forma verbal en la superficie; el objeto el sujeto.

113. Los glaciares abundan en Suiza.

114. El bulto no cabe en la gaveta.

115. Los Ramírez viven en la Paulina.

116. El muerto yace en su tumba.

117. El monumento se encuentra en el Parque $E$ paña.

C. La forma verbal en la superficie; el locativ es el sujeto.

118. La caja contiene juguetes $=$ En la caja ha juguetes.

119. El libro consta de 100 páginas $=$ En el libr hay 100 páginas.

120. El desierto abarca mucho terreno $=E n$ desierto hay mucho terreno.

Cabe recordar que cualquier oración en esp: ñol admite una expresión de lugar, pero a menc que esté exigido por el verbo, ésta no forma part de la proposición sino que pertenece a la modal dad. Los casos de la modalidad siempre son facu tativos. 
Verbos locativos de proceso $[-O, L]$

El verbo implica el cambio de posición de un objeto y puede enfocar el momento del cambio, o el inicio o el fin del cambio. Cuando el lugar implicado por el verbo no se manifiesta, la categoría de lugar permanece implícita en la mente.

121. El niño se cayó (del árbol).

122. El niño se cayó (al suelo).

123. El niño se está cayendo (de o a un lugar);

124. El cadáver llegó a la morgue.

125. El avión llegó (a un lugar conocido por la persona que pronuncia la oración y por la persona que la oye).

126. El avión partió (de un lugar conocido).

127. Los reos se escaparon de la cárcel.

Verbos locativos de acción [ $A$, L]

Superficialmente en la oración hay sólo dos argumentos, el agentivo y el locativo; pero, como en todos los demás ejemplos, siempre hay un objeto implícito. Con los verbos locativos de acción el agente de la acción puede ser, a la vez, el objeto que se desplaza en el espacio, de modo que puede haber correferencialidad de relaciones semánticas.

\section{El investigador llegó a la morgue.}

Esta oración es representativa de la categoría de verbos locativos de acción si 'el investigador' llegó a la morgue por su propia voluntad. 'El investigador' hizo algo ('llegó a la morgue') y a la vez es el objeto desplazado de un lugar a otro. El agente $y$ el objeto son correferenciales. Si 'el investigador' llegó a la morgue porque lo llevaron muerto o inconsciente, la oración es representativa de la categoría de verbos locativos de proceso y no de acción.

Otros ejemplos de verbos locativos de acción son:

129. Los turistas viajaron a París.

130. El avión voló a Roma.
131. Somoza abandonó Nicaragua.

132. Los ingleses ocuparon las Malvinas.

133. No pisen el césped.

De 131 a 133 el locativo tiene la forma de un complemento directo, sin preposición.

En los siguientes ejemplos, el objeto está presente en la oración, pero está lexicalizado en el verbo:

134. Goya pintó a las desnudas - 'puso pintura en las desnudas'.

135. El vecino pintó la casa.

136. El campesino plantó su finca - 'puso plantas en su finca'.

137. Los hombres descargaron el vagón - 'sacaron las cargas del vagón'.

138. Los hombres cargaron el vagón - 'pusieron la carga en el vagón'.

\section{Verbos locativos de acción-proceso \\ $[-\mathrm{A}, \mathrm{O}, \mathrm{L}]$}

Hay un objeto que cambia de lugar por causa de un agente. La manifestación superficial del lugar es obligatoria, o el lugar puede estar implicitamente presente o puede estar lexicalizado en el verbo.

139. El ama de casa puso un huevo sobre la mesa.

Se ve la necesidad de especificar el lugar, pues si no se especifica hay un cambio radical en el significado de la oración.

140. El chofer llevó al pasajero al centro de la ciudad.

141. El hombre se me acercó.

En 141 'el hombre' manifiesta el caso agentivo; 'se', refiriéndose al hombre, manifiesta el caso objetivo; y 'me' manifiesta el caso locativo ('a mí' es el lugar adonde el hombre se acercó).

142. Colgaron el cuadro en la pared. 
143. Juan me devolvió el libro. (Compárese: Juan devolvió el libro a la biblioteca).

144. EI MOPT colocó señales de tránsito a lo largo de las carreteras.

En 143 y 144 el locativo puede no expresarse en la oración, pero siempre queda implícita la categoría. De igual manera:

145. El campesino sembró maíz (en su finca).

146. Alguien llenó el pichel (de agua).

En esta oración, 'el pichel' manifiesta el caso locativo y 'agua' el caso objetivo.

\section{Alguien vació el agua del pichel.}

Las relaciones semánticas de 146 y 147 son iguales; las diferencias son formales. En 146 el locativo tiene la forma de un complemento directo $y$ el objetivo va acompañado de una preposición; en 147 el objeto tiene la forma de un complemento directo y el locativo va acompañado de una preposición.

148. Los trabajadores enlataron la cerveza.

149. El taxista se orilló.

150. El general arrinconó a su enemigo.

De 148 a 150 el locativo está lexicalizado en el verbo. En 148 los trabajadores pusieron la cerveza en latas. En 149 el taxista se trasladó a sí mismo (en su automóvil) a la orilla. En 150 el general llevó a un rincón a su enemigo.

El verbo 'ir' permite no expresar el locativo, manifestando la forma refleja, 151 no es gramatical, a diferencia de 152, en la cual 'se' indica 'de' o 'a' un lugar determinado.

151. *El hombre fue.

152. El hombre se fue.

Sin la forma refleja, 'ir' exige la especificación del locativo.

153. El hombre fue a Cartago.
Con la forma refleja, 'ir' permite que también se especifique el lugar exacto de, o a donde, fue el hombre.

154. El hombre se fue de aquí.

En todas las lenguas del mundo el verbo (operador lógico) manifiesta cuatro clases de rasgos:

A. Rasgos léxicos. Estos son los rasgos semánticos propios de un verbo o sustantivo que indican su significado léxico.

B. Rasgos inflexionales. Estos provienen de la modalidad y pueden o no tener una manifestación explícita, pero siempre están presentes en la mente. Los rasgos incluyen tiempo $y$ aspecto de toda clase que no sean parte inherente del rubro léxico.

C. Rasgos relacionales. Esta es una de las dos áreas de especial interés para la Gramática de casos (la otra es la de los rasgos derivacionales). Como se ha indicado ya, estos ragos son los que señalan la relación semántica, llamada 'relación casual', entre los sustantivos (que son las manifestaciones de argumentos o variables lógicas) y un verbo (que es la manifestación de un operador lógico y puede tomar la forma superficial de un verbo, un adjetivo, un sustantivo, un cuantificador, etc.). Es axiomático que todas las lenguas manifiestan de alguna manera estados simples, estados experientivos, estados benefactivos, estados locativos, procesos simples, procesos experientivos, procesos benefactivos, procesos locativos, acciones-procesos, acciones-procesos experientivos, acciones-procesos benefactivos y acciones-procesos locativos. Debido a la relación semántica que hay entre las acciones simples, acciones experientivas, acciones benefactivas $y$ acciones locativas, y las mismas categorías que incluyen también el proceso, estas dos subdivisiones pueden ser agrupadas juntas en una lengua, o pueden mantenerse separadas. La principal diferencia entre una y otra lengua consiste en los rubros léxicos que manifiestan las diferentes categorías.

Walter Cook (1972, repetido en Aid 1973) ha ofrecido un cuadro que resume lo que él propone como la lista universal de rasgos 
relacionales proposicionales basados en el hecho de estar implicados por el verbo. Cualquier otro rasgo relacional que pueda exis- tir (el instrumental, por ejemplo) es parte de la modalidad. En el cuadro que sigue incluyo ejemplos del español:

\section{VERBO CASO}

\begin{tabular}{|c|c|c|c|c|c|c|c|}
\hline Estado & $\mathrm{O}_{\mathrm{e}}$ & $\begin{array}{l}\text { Estado } \\
\text { Experientivo }\end{array}$ & $\mathrm{E}_{\mathrm{e}} \mathrm{O}$ & $\begin{array}{l}\text { Estado } \\
\text { Benefactivo }\end{array}$ & $\mathrm{B}_{\mathrm{e}} \mathrm{O}$ & $\begin{array}{l}\text { Estado } \\
\text { Locativo }\end{array}$ & $\mathrm{O}_{\mathrm{e}} \mathrm{L}$ \\
\hline $\begin{array}{l}\text { blanco } \\
\text { existir } \\
\text { payaso } \\
\text { costar }\end{array}$ & & $\begin{array}{l}\text { necesitar } \\
\text { querer } \\
\text { parecer }\end{array}$ & & $\begin{array}{l}\text { tener } \\
\text { pertenecer } \\
\text { poseer }\end{array}$ & & $\begin{array}{l}\text { en } \\
\text { sobre } \\
\text { vivir (residir) }\end{array}$ & \\
\hline 1.1 & & 1.2 & & 1.3 & & 1.4 & \\
\hline $\begin{array}{l}\text { Proceso } \\
\text { morir(se) } \\
\text { crecer } \\
\text { diormir } \\
\text { quebrarse }\end{array}$ & 0 & $\begin{array}{l}\text { Proceso } \\
\text { Experientivo } \\
\text { doler } \\
\text { asustar } \\
\text { divertir }\end{array}$ & EO & $\begin{array}{l}\text { Proceso } \\
\text { Benefactivo } \\
\text { encontrar } \\
\text { ganar } \\
\text { heredar }\end{array}$ & BO & $\begin{array}{l}\text { Proceso } \\
\text { Locativo } \\
\text { caer(se) } \\
\text { llegar } \\
\text { subir }\end{array}$ & $\mathrm{OL}$ \\
\hline 21 & & 2.2 & & 2.3 & & 2.4 & \\
\hline $\begin{array}{l}\text { Acción } \\
\text { cantar } \\
\text { correr } \\
\text { jugar }\end{array}$ & $A$ & $\begin{array}{l}\text { Acción } \\
\text { Experientivo } \\
\text { asustar } \\
\text { divertir } \\
\text { lastimar }\end{array}$ & $\mathrm{AE}$ & $\begin{array}{l}\text { Acción } \\
\text { Benefectivo } \\
\text { sobornar } \\
\text { ayudar } \\
\text { besar }\end{array}$ & $A B$ & $\begin{array}{l}\text { Acción } \\
\text { Locativo } \\
\text { viajar } \\
\text { abandonar } \\
\text { pisar }\end{array}$ & $A L$ \\
\hline 3.1 & & 3.2 & & 3.3 & & 3.4 & \\
\hline $\begin{array}{l}\text { Acción } \\
\text { Proceso }\end{array}$ & $\mathrm{AO}$ & $\begin{array}{l}\text { Acción } \\
\text { Proceso } \\
\text { Experientivo }\end{array}$ & $A B O$ & $\begin{array}{l}\text { Acción } \\
\text { Proceso } \\
\text { Benefactivo }\end{array}$ & $\mathrm{ABO}$ & $\begin{array}{l}\text { Acción } \\
\text { Proceso } \\
\text { Locativo }\end{array}$ & $\mathrm{AOL}$ \\
\hline $\begin{array}{l}\text { matar } \\
\text { pintar } \\
\text { escribir } \\
\text { quebrar }\end{array}$ & & $\begin{array}{l}\text { decir } \\
\text { mostrar } \\
\text { escribir }\end{array}$ & & $\begin{array}{l}\text { comprar } \\
\text { robar } \\
\text { pagar }\end{array}$ & & $\begin{array}{l}\text { poner } \\
\text { traer } \\
\text { enlatar }\end{array}$ & \\
\hline 4.1 . & & 4.2 & & 4.3 & & 4.4 & \\
\hline
\end{tabular}

Como se ve en el cuadro, algunos verbos pueden entrar en más de una relación semántica con el verbo o tienen cabida en más de una relacićn por medio de una derivación. 'Escribir' en 4.1 es diferente de 'escribir' en 4.2. La diferencia se mota en
156. Benavente escribió La Malquerida.

157. Mi tía me escribió una carta.

'Escribir' en 156 no implica 'a alguien' mientras que sí en 157. Se ha hablado de otros ejemplos en el texto. 
D. Rasgos derivacionales. Cook, en dos oportunidades, ha ofrecido listas diferentes de lo que él propone como el repertorio univer- sal de rasgos derivacionales. La primera lista puede esquematizarse así:

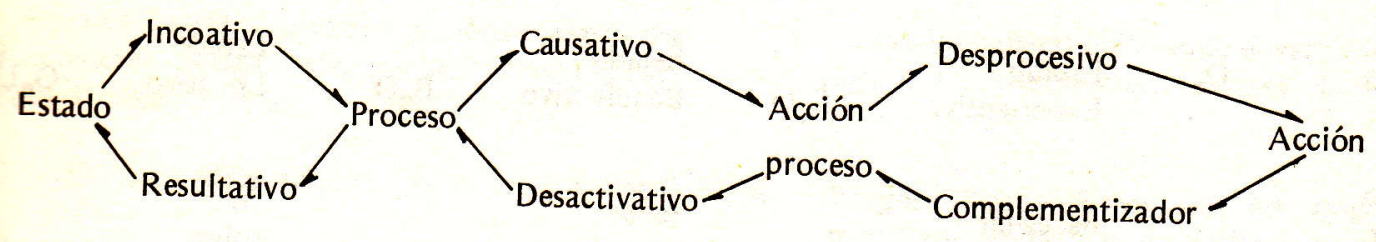

La segunda lista la modifica, quitando 'acción', y, por lo tanto los rasgos derivacionales 'desprocesivo' y 'complementizador', por considerar que 'acción' es una simple manifestación de 'acción-proceso'. En este trabajo mantenemos básjcamente la lista original puesto que el español manifiesta diferencias formales, aún cuando pueden ser superficiales, entre las dos categorías. Es posible señalar ciertas relaciones que existen entre diferentes proposiciones. Por ejemplo, en español el verbo básico de estado marca estados inherentes o 'naturales' (desde un punto de vista conceptual) con la forma 'ser', que es una forma superficial sin valor semántico propio. Así decimos en español:

158. El cielo es azul.

Si el cielo cambia de estado, un proceso, podemos decir algo así como:

159. El cielo se nubló.

Aquí 'se' marca un incoativo e indica el cambio estado. Con el verbo conjugado en el pasado perfectivo, 'se' marca el fin del proceso. El estado que resulta de un proceso se marca superficialmene con la forma 'estar', y el resultado es:

60. El cielo está nublado.

\section{Si}

61. El cielo se aclaró

tro proceso) y vuelve a su estado 'natural', decilos que:

52. El cielo está (otra vez) azul.
Al contrario de la creencia popular, la diferencia entre las cópulas 'ser' y 'estar' no está sino indirectamente relacionada con la idea de temporalidad. 'Ser' marca un estado inherente, $y$, por consiguiente, puede indicar una condición de más duración en el tiempo, y 'estar' marca un estado resultante que por serlo puede ser de menos duración. Que la temporalidad esté reflejada sólo indirectamente, se ve en los siguientes ejemplos:

163. El elefante está muerto.

164. El novio de Isabel vive borracho.

165. El novio de Isabel vive en la cantina.

En 163 el resultado del cambio de estado no puede ser más permanente. En 164 y 165 'vivir' es equivalente a 'estar siempre' (con su sujeto animado), y, por lo tanto, agrega la idea de duración al resultado del proceso. Si 'ser' indica duración y 'estar' poca duración, 'vivir' debe ser equivalente a 'ser' pero vemos que esto no es cierto porque 'vivir' no puede aparecer con operadores que señalan una relación básica de estado inherente; sólo puede aparecer con operadores que señalan una relación básica de estado resultante:

166. *Esa mujer vive gorda.

167. *El carpintero vive hábil.

168. Ese hombre vive feliz.

169. Ese hombre vive aburrido.

'Vivir' acompaña los mismos operadores que 'estar', con excepción de dos: 
*El hombre vive vivo.

*El hombre vive muerto.

170 y 171 hay una incongruencia semántica ve en la imposibilidad de decir:

*El hombre siempre está vivo.

*El hombre siempre está muerto.

168 y 169 la condición puede cambiar y a cambiar porque el sujeto de las oraciowede ejercer cierto control sobre ella. En 170 2 el sujeto puede ejercer un control sobre su ición suicidándose; pero, una vez cambiada, vede volver a la condición original. En 171 y - na persona no puede vivir una condición és de muerto, como tampoco puede volver ndición que existía antes del cambio. 'Vivir', no puede entrar en predicaciones que tratan diciones absolutas; sólo puede usarse cuancondición es relativa. Sin embargo, es posible

El hombre vive muerto de susto.

El hombre siempre está muerto de susto.

estado que resulta de un proceso puede no sino psicológico, como cuando se dice:

El Presidente está vivo.

I situación social en que una oración como podría producirse sería aquella en la cual se pensar que estaba muerto. La fuerza sede la oración es:

El Presidente no está muerto.

la siguiente oración la condición deseada no dado:

Este zapato está muy grande.

números 176 y 178 muestran la desviación norma potencial o esperada. Compárense ientes oraciones:

El viento es muy fuerte.

iQué fuerte es el viento!
181. ¡Qué fuerte está el viento!

En 179 y 180 hay una caracterización de 'viento', marcada con 'ser'. 181 representa una reacción psicológica por parte del hablante, que puede ser de sorpresa, de desagrado, etc., ante alguna situación basada en una experiencia inmediata, y encierra la idea de un grado relativo en la caracterización de un estado. Oraciones como 181 sólo pueden darse con operadores que normalmente se marcan con 'ser', o con 'estar' cuando el estado caracterizado no es absoluto sino relativo.

182. ¡Qué listo está el niño!

sólo puede provenir de

183. El niño es listo.

No puede provenir de

184. El niño está listo.

Inaceptable resultaría ser

185. * iQué muerto está el terrorista!

186. * iQué quebrada está la ventana!

No puede darse porque

187. La ventana está quebrada.

representa un estado absoluto. Compárense

188. Estoy cansado y

189 iQué cansado estoy!

en que 'estar cansado' representa un estado relativo.

Los verbos simples de proceso en español se dividen formalmente en dos clases: de proceso inherente $y$ de proceso derivado. En el último caso, se pueden derivar procesos de estados mediante el rasgo incoativo, o de acciones-procesos mediante el rasgo desactivativo.

Los procesos inherentes se distinguen porque, si bien algunos pueden marcarse con 'se', éste no es obligatorio:

190. (Se) murió el perro. 
191. El niño está durmiendo.

192. El estudiante 'sonó' (en el examen).

193. Falló el motor.

194. La fiesta será (tendrá lugar) a las ocho.

195. Estalló una bomba.

196. Pedro (se) enfermó.

197. Creció el maíz.

198. Nació un varón.

Los procesos derivados se marcan en español obligatoriamente con 'se', aun cuando el proceso mismo puede estar lexicalizado:

199. Se pegó la ventana.

200. Se abrió la puerta.

201. Se secó la ropa.

202. El borracho se volvió loco.

203. La muchacha se puso colorada.

204. Enrique VIII se volvió hereje.

205. Ese hombre se hizo el maje.

206. La rana se convirtió en príncipe.

El lenguaje humano refleja tres grandes factores: la situación social (extralingüística) en que se produce un discurso; modificaciones introducidas a las relaciones semánticas básicas de la proposición, tales como de tiempo, aspecto y modo, si la oración va a ser declarativa, imperativa, interrogativa, negativa, etc.; y las relaciones semánticas que forman base, sin modificación, de la proposición.

Hasta aquí se ha hablado con algún detalle de estados y de procesos. En relación con estas dos categorías, el hablante puede enfocar una situación social desde tres perspectivas: puede enfocar un estado como característica inherente; puede enfocar un proceso; o puede enfocar el estado que resulta de un proceso. Ejemplos de esto son las siguientes oraciones:
207. Fígaro es casado (es su estado concebido como natural).

208. Fígaro se casó (cambió su estado).

209. Fígaro está casado (es el resultado de haberse casado).

Los verbos experientivos de proceso pueden introducir una ambigüedad:

210. El profesor se aburrió (su estado natural pro duce un efecto en nosotros).

211. El profesor (nos) aburre (nosotros cambi mos de estado).

212. El profesor está aburrido (la oración es bigüa: o él o nosotros cambiamos de esta y el aburrimiento es el resultado).

Los sustantivos que fungen como operado también pueden ser contemplados, en algunos $c$ sos, desde estos tres puntos de vista:

213. La casa es un desastre (una característic inherente o 'normal').

214. La casa se convirtió en un desastre (donde incoativo está lexicalizado).

215. La casa está hecha un desastre (en un estad que resultó de un cambio de estado).

Los verbos que son inherentemente de estad pueden convertirse en verbos de proceso al agr gárseles el rasgo íncoativo, y éste generalmente marca de alguna manera en la superficie:

216. Las manzanas son (naturalmente) rojz

217. La muchacha se sonrojó.

218. La muchacha enrojeció.

219. La muchacha se puso roja.

Verbos como 'blanco' pueden entrar en vario tipos de derivaciones:

220. La ropa es blanca (su estado normal

Si a esto le agregamos el rasgo incoativo, el re sultado es: 
Se puso blanca la ropa.

Con el rasgo resultativo, tenemos:

22. La ropa está blanca.

El rasgo incoativo puede lexicalizarse en el uerbo:

203. Se blanqueó la ropa.

Con el rasgo resultativo, tenemos:

24. La ropa está blanqueada.

$Y$ con el rasgo causativo:

225. La mujer blanqueó la ropa.

Los verbos de proceso pueden ser derivados de uerbos de acción-proceso, y los verbos de acdiön-proceso pueden ser inherentes o derivados de procesos o de acciones. Ejemplos del primero se ven en 223 y 225.

Otros ejemplos son:

226. Los peones quemaron el monte.

227. El profesor 'sonó' a los estudiantes.

228. La mujer durmió al niño.

'Cocinar' es un verbo que es inherentemente de acción-proceso:

229. Mamá está cocinando las papas.

La oración manifiesta de manera explícita agente ('mamá'), que 'hace' algo, y un objeto (Ilas papas') que recibe la acción (lo que Bello llamaba 'paciente'). Lo que pasa con verbos de esta ategoría en derivaciones es bastante interesante en español.

230. Mamá está cocinando.

El rasgo desprocesivo convierte, superficialmenIs, un verbo de acción-proceso en un verbo de simple acción. Los verbos de acción-proceso implican dos argumentos manifiestos en la superficie: un agente y un objeto, además de cualquier otro argumento implícito. En 230, la superficie no manifies- ta el argumento 'objeto', pero éste permanece implícito en la mente: se sabe que 'Mamá está cocinando algo'. De hecho, los verbos de acción simple, como se ha indicado ya, implican dos argumentos, de modo que la diferencia entre verbos de acción y verbos de acción-proceso es una simple diferencia formal y no semántica.

Cuando el verbo de acción-proceso se deriva en verbo de proceso, mediante el rasgo desactivativo, se saca totalmente de perspectiva al agente. $\mathrm{Si}$ al verbo 'cocinar' se le agrega el rasgo desactivativo podríamos tener como resultado una oración como:

\section{Las papas se están cocinando.}

En 231 no hay agente ni explícito ni implícito. La relación semántica entre 'las papas' y el verbo sigue siendo la misma que en 229; pero, al no haber un agente en la oración, el objeto se convierte en sujeto, resultado demostrado por la concordancia verbal.

Si bien el clítico 'se' tiene varios usos gramaticales en español, su utilización en oraciones con verbos derivados forma parte del sistema de topicalización (y destopicalización) del idioma. Compárense los siguientes conjuntos de oraciones:

\section{Mamá cocinó las papas.}

233. Las papas las cocinó mamá.

234. Las papas fueron cocinadas (por mamá).

235. Se cocinaron las papas.

236. Colón descubrió América en 1492.

237. América la descubrió Colón en 1492.

238. América fue descubierta (por Colón) en 1492.

239. Se descubrió América en 1492.

Las oraciones 232 y 236 son simples oraciones declarativas no afectivas (si no hay alguna modificación en el patrón normal de entonación). En toda oración en español, se reconoce el sujeto por la concordancia que muestra el verbo. En español toda información incluida en una oración declarativa puede ser considerada por parte del hablante como nueva para el oyente, o sólo una parte de 
ella. Cuando en una comunicación hay información vieja (en el sentido de ya conocida) y nueva, el español tiende a establecer primero el tema, es decir, de lo que se va a hablar (siempre un sintagma nominal, o argumento) y, por lo tanto, da una perspectiva a la oración introduciendo desde el primer momento la información vieja para hacer un comentario sobre ella, e introduce la información nueva a la derecha (todo en el sentido de que se lee de izquierda a derecha). En 232 toda la información puede ser nueva, pero si sólo una parte es nueva (haciendo caso omiso de variantes posibles debido a cambios entonacionales), esta parte tiene que ser, o el verbo más el objeto, o sólo el objeto. En realidad en 232 el uso de la palabra 'mamá' es una indicación de que el oyente tiene que saber a quien se está refiriendo el hablante y que por lo menos esa parte de la oración es información vieja. 'Mamá', pues, es, a la vez, el sujeto de la oración, el tema de la oración y constituye la información vieja de la oración. También es el agente de la acción de 'cocinar'.

En 233 se ha topicalizado el objeto, 'las papas', dislocándose hacia la izquierda pero dejando atrás un rastro en la forma del clítico 'las', y desplazando a 'mamá' al final. De esta manera 'mamá' constituye la información nueva y se topicaliza 'las papas'. El agente, 'mamá', ha pasado a un segundo grado de topicalización, si bien sigue siendo el sujeto de la oración.

En 234 encontramos una oración pasiva en la cual el objeto, además de haberse topicalizado, se ha convertido en el sujeto y el agente está manifiesto en una construcción oblicua. Si el agente en la pasiva manifiesta información nueva, se mantiene pero ya en un tercer grado de (des) topicalización. Si el verbo, o un complemento del verbo que no sea el agente, manifiesta la información nueva, el agente en la pasiva se omite, y estamos frente a un cuarto grado de topicalización.

En 235 encontramos la destopicalización completa del agente. El objeto es sujeto y tema, y es, además, el único argumento implícito en la oración. Si bien el agente puede manifestarse o no en la construcción pasiva, $y$, por lo tanto, la oración sigue manifestando la categoría de acción-proceso, el rasgo desactivativo sólo permite la manifestación de un proceso. La desactivación de 235 se ve en la poca aceptabilidad (o ninguna) de

\section{0. * Las papas se cocinaron por mamá.}

Aquí el agente no puede manifestarse. La falta de un agente implícito se ve en:

\section{Las papas se cocinaron solas.}

En esta oración el agente queda por compl to excluido. Se pueden aplicar los mismos ran namientos para las oraciones de 236 a 239.

Es interesante ver que Andrés Bello notz la desactivación del verbo en esta clase de con trucciones cuando afirma lo siguiente:

\begin{abstract}
'Otras construcciones regulares cuasi-reflejas son de tercera persona, formadas con verbos ordinari mente activos; $y$ por su uso frecuente puede decins que pertenecen al proceder ordinario de la conjum ción... De la reflexivilidad significada por los eleme tos gramaticales, la idea de acción se desvanece, queda solamente la idea de pasión [es decir, qued la idea manifestada por el 'paciente', u 'objeto' (JW o de modificación recibida'. (767).
\end{abstract}

Tanto Bello como Samuel Gili y Gaya relacio nan estas 'construcciones regulares cuasi-reflejas con las construcciones pasivas. Gili y Gaya, po ejemplo, afirma que

\begin{abstract}
'...Ia construcción activa "La radio ha divulgado esta noticias" tiene en pasiva las expresiones "Estas not cias han sido divulgadas por la radio" o "Se han divul gado estas noticias por la radio". Si desaparece el inta rés hacia el sujeto agente diremos... "Se han divulgad estas noticias"' (57).
\end{abstract}

Pienso que la posición de Bello contradice la d Gili y Gaya. Si bien Bello relaciona la construcción cuasi-refleja con la pasiva, da a entender que es pasiva sin agente explícito ni implícito. Para Gili Gaya, en cambio, las dos construcciones son prác ticamente equivalentes. Gili y Gaya confunde que es agente (algo que por sí solo es capaz de rez lizar una acción) y lo que es medio o instrument (algo de que se sirve el agente para realizar una ac ción), y vale decir que esta diferencia tiene conse cuencias sintácticas en español. Véanse las siguien tes oraciones:

242. El conserje abrió la puerta.

243. El conserje abrió la puerta con la llave.

244. La puerta fue abierta por el conserje.

245. La puerta fue abierta con la llave por el con serje.

246. La llave abrió la puerta. 
* La puerta fue abierta por la llave.

La puerta fue abierta con la llave.

"La llave abrió la puerta por (o, con) el conserje.

"Se abrió la puerta por la llave.

Se abrió la puerta con la llave.

la oración 245 vemos que el marcador obliinstrumento es 'con' y del agente es 'por'. ma oración están presentes el agente y el insto, sólo el agente puede fungir como el sula oración activa. Si en la oración activa no olícito un agente, el instrumento pasa a ser to y en la oración no hay agente implícito. demuestra por la imposibilidad de introduagente, como se ve en 249. En oraciones que asicamente de acción-proceso, el español la transformación de la oración activa en únicamente cuando el sujeto es un agente. se debe la agramaticalidad de 247 . El insto, marcado con 'con', está presente en la 248 , y el agente ha sufrido una elisión faCompárese:

La puerta fue abierta con la llave (por alguien).

a confusión para Gili y Gaya se debe a la forde la preposición 'por', que, a la vez que es eposición que se asocia con el agente, es la * usa para introducir el medio (que es una fiestación específica del caso instrumental).

fanse las siguientes oraciones:

Mandaron la carta por correo, por avión, por barco, etc.

El locutor ha divulgado estas noticias por la radio.

doble papel de 'por' se ve en la oración 255, que corresponde a la oración 245 en , en lugar de un 'medio', hay un 'instruto (no-medio)':

Estas noticias han sido divulgadas por la radio por el locutor.
Veamos el paralelismo que hay entre los dos conjuntos de oraciones:

256. El conserje abrió la puerta. (Agente y objeto).

El locutor ha divulgado estas noticias. (Agente $y$ objeto).

257. El conserje abrió la puerta con la llave. (Agente, objeto e instrumento).

El locutor ha divulgado estas noticias por la radio. (Agente, objeto y medio).

258. La puerta fue abierta por el conserje. (Objeto $y$ agente)

Estas noticias han sido divulgadas por el locutor (Objeto y agente).

259. La puerta fue abierta con la llave por el conserje. (Objeto, instrumento y agente). Estas noticias han sido divulgadas por la radio por el locutor. (Objeto, medio y agente).

260. La llave abrió la puerta. (Instrumento y objeto)

La radio ha divulgado estas noticias. (Medio y objeto).

261. * La puerta fue abierta por la llave. (Objeto y agente)

* Estas noticias han sido divulgadas por la radio. (Objeto y agente).

262. La puerta fue abierta con la llave. (Objeto e instrumento)

Estas noticias han sido divulgadas por la radio. (Objeto y medio).

263. * La llave abrió la puerta por/con el conserje. (Instrumento, objeto y agente).

* La radio ha divulgado estas noticias por/con el locutor. (Medio, objeto y agente).

264. * Se abrió la puerta con la llave. (Objeto y agente).

* Se han divulgado estas noticias por la radio. (Objeto y agente).

265. Se abrió la puerta con la llave. (Objeto e instrumento).

Se han divulgado estas noticias por la radio. (Objeto y medio). 
Creo que estos ejemplos constituyen una prueba a favor de la posición de Bello y demuestran el error de Gili y Gaya, y que refuerzan el argumento del presente trabajo en el sentido de que las formas con 'se' tienen como resultado la destopicalización, o desenfoque, total de lo que de otra manera sería el agente de una oración. En esta discusión está implícita la tesis de que las construcciones con 'se' no tienen nada más que ver con las construc. ciones pasivas que éstas con las correspondientes activas. De hecho, tienen menos que ver puesto que las oraciones pasivas pueden incluir toda la información contenida en las correspondientes activas, mientras que las oraciones con 'se' excluyen parte de esa información de manera obligatoria. Las pruebas indican que es un error hablar de una 'pasiva con "se", como si esta clase de construcción fuera una simple variante de la verdadera construcción pasiva, como lo hace, por ejemplo, Gili y Gaya, cuando afirma que 'Si desaparece el interés hacia el sujeto agente diremos: "...Se han divulgado estas noticias". En este último caso nos hallamos en los límites que separan las oraciones pasivas de las impersonales' (57). Las pruebas indican que se trata de dos construcciones completamente diferentes, si bien ambas forman parte del sistema de topicalización del idioma.

El clítico 'se' tiene varias funciones en español. Totalmente carente de interés teórico por obedecer a una regla fonológica, es el cambio de 'le 10 ' en 'se lo', como en:

266. El libro se lo di a mi primo.

De más interés son las siguientes funciones:

A. Cuando dos argumentos o partes de argumentos de una proposición son correferenciales. Algunos ejemplos son:

i) Cuando el agente es correferencial con el objeto:

267. Elena se bañó.

268. El bañista se desnudó.

269. El gato se subió al árbol.

Cuando los argumentos son complejos, las formas con 'se' abarcan la reciprocidad y la distribución:
270. Los muchachos se vieron en el espei

271. Los pandilleros se dieron de golpes.

ii) Cuando el agente es correferencial com benefactivo:

272. El niño se hizo un emparedado.

273. La mujer se compró un vestido nue

iii) Cuando el benefactivo es correferenci con el objeto:

274. Yo no me pertenezco.

iv) Cuando el experientivo es correferenc con el objeto:

275. Esa persona se quiere a sí misma.

v) En construcciones de posesión inalier ble, cuando el agente es correferenci con el posesor $y$, por lo tanto, form parte del objeto, el posesor toma la f ma superficial de un dativo:

276. El hombre se lavó la cara. ('La cara' ma fiesta la relación casual de locativo).

\section{Compárese con}

\section{7. *EI hombre lavó su cara,}

que suena poco natural, $y$ con

278. El hombre lavó su carro,

que es perfectamente natural. En esta oración posesión se manifiesta con la forma superficial un genitivo y el valor semántico es de un benefa tivo.

B. Como parte inherente del verbo:

279. El muchacho se ve triste.

En esta oración, 'el muchacho', no hace nad es decir, el significado no es que 'el muchac' se ve'. El impacto semántico de la oración es que un espectador experimenta la sensación que el muchacho tiene un aspecto de tristez Se encuentra una situación análoga en: 
Juan se (me) parece a su hermano.

\section{El hombre se fue, o}

Se subió el hombre al árbol,

mbre' es a la vez agente y objeto y el espapermite la manifestación explícita de ambas ones con la forma refleja en oraciones que icialmente son intransitivas. En 281 el uso ' también permite el desenfoque del locative es implicado por todo verbo que involumovimiento. Compárese 281 con

*El hombre fue.

del verbo 'ir', exige un complemento loca-

Como reemplazante del sujeto.

español es una lengua que permite marcar dies clases de redundancias. Entre los más noejemplos de marcación redundante se enan las desinencias verbales. Si la esposa le diesposo

\section{Tú roncas,}

final del verbo debe su existencia al 'tú' suEs tal la fuerza de la redundancia que el espauego permite la elisión del pronombre, que portador original de la información semánobre e! sujeto, y sin ambigüedad se puede de-

\section{Roncas.}

las desinencias de la tercera persona exisposibilidad de algún grado de ambigüedad, Ésta debe quedar aclarada por la situación en que tales oraciones se generan.

Eaiste un subsistema de redundancias en esque se designa como 'clíticos'. Obsérvensiguientes oraciones:

Hablé a la mujer.

Le hablé a la mujer.

Le hablé a ella.

289. *Hablé a ella.

290. Le hablé

En español los complementos del verbo siempre se generan después del verbo, como en 286. Cuando tenemos un complemento introducido por ' $a$ ', cuando éste no indica un locativo, se da origen al clítico, que en el caso de la tercera persona del singular se manifiesta como 'le' o 'lo, la'; la forma en sí está determinada por diferentes factores que no son de interés en este trabajo. El clítico no es la fuente de la información sino el reflejo de la información, como se ve en 287 y 288 . Que sea un fenómeno superficial se ve en 289 , en la cual toda la información necesaria está presente pero la oración es agramatical. En 290 se ve que la redundancia refleja la información de manera tan completa que lo que le dio origen puede ser elidido. 290 es más ambigua que 288 , pero, en ambos casos, se requiere de un contexto para resolver las ambigüedades.

El español tiene dos subconjuntos de clíticos oblicuos:

I

me

te

le, lo, la, les, los, las

Estos tienen su origen en:

a mí a nosotros a mí mismo a nosotros (mismos)

a tí a vosotros a ti (mismo) a nosotros (mismos a él, a ella a ellos, a ellas a sí (mismo) a sí (mismos) a Ud. a Uds.

La diferencia de selección entre 'le(s)', por un lado, y 'lo(s), la (s)', por otro, está determinada por el verbo. Las formas 'le, les' pueden tener un origen 'a + sustantivo'.

Sería un error decir que las formas 'me, te, le, lo, se, etc.' son pronombres. Los pronombres, - los sustantivos, cuando es del caso, son los que les dan existencia. Una derivación podría ser comos sigue: 
291. *Veo a el libro (la forma que se genera desde la estructura profunda).

292. Veo el libro (con elisión de 'a' si lo que sigue es [-animado]).

293. Veo a el hombre (como 'hombre' es [ + animado], ' $a$ ' se mantiene y sufre una contracción con el artículo siguiente).

294. Veo a él (la manifestación de 291 o de 193 si en lugar de un sustantivo se genera un pronombre).

295. Lo veo a él (el resultado de la regla de creación del clítico a partir de 294 y de su colocación en la posición correcta).

296. Lo veo (el resultado de la regla obligatoria de elisión de 'a + pronombre' si éste es [-animado]; la elisión es facultativa si el pronombre es [+ animado]).

En todos los casos, el clítico funciona, no como pronombre sino como portador redundante de la información expresada por el pronombre, o en algunos casos especiales por el sustantivo que le dio origen. La única información que no manifiesta el clítico es en el caso de la diferencia entre Ud(s)., él (ellos) y ella(s), y de esto tiene que encargarse el contex to social.

$\mathrm{Al}$ igual que los clíticos que corresponden a complementos post-verbales, los clíticos que corresponden a sujetos tiene sus propias características. El origen del clítico en función de complemento es exclusivamente formal ('a + pronombre/sustantivo'); pero hay, por lo menos, cuatro fuentes del clítico que corresponde al sujeto. Estos clíticos tienen la forma del subconjunto II de los clíticos oblicuos.

i) En algunos casos, la exigencia o la posibilidad de la manifestación del clítico está determinada de manera sui géneris por el verbo. Tal es el caso en los siguientes ejemplos:

297. El jugador se lamentó de su suerte.

298. iNo se queje tanto!

299. Los niños se reían. ii) El clítico puede aparecer cuando un argumento implicado por el ver como en los siguientes casos en los cu el verbo normalmente exige la manifes ción de una expresión locativa:

300. Al fin se fue la visita.

301. El taxista se llevó a los pasajeros.

En todos los casos en los cuales el clítico corr ponde a un complemento, es posible manifestar pronombre (o el sustantivo) que le dio origen. bien es cierto que el español no permite la comar festación en ejemplos como el siguiente:

302. * Lo vi a él (cuando el pronombre está m cado [-animado], la comanifestación se en dislocaciones, como, por ejemplo:

303. El libro lo vi ayer.

iii) En cuanto a los clíticos que correspond a sujetos, en los ejemplos que se han da: hasta ahora, también es posible la comar festación del clítico y el pronombre os: tantivo al cual corresponde formalment En los siguientes casos, el clítico corre ponde a un sujeto que tiene rasgos per no tiene forma. Como sucede en estos c sos en español, este sujeto vacío tiene rasgos de tercera persona y de singula

En oraciones derivadas cuando el objeto es marcado como [-animado] el 'se' no tiene orige nominal, sino que es el marcador del proceso y concordancia verbal está con el objeto, que, por tanto, funciona como el sujeto de la oración

304. Se abrieron las puertas.

305. Se alquilaron las casas.

Cuando el objeto está marcado como [+ anim do], pueden presentarse problemas.

306. Se asustaron los niños por (causa de) la o curidad.

307. Los niños se asustaron.

En 306, 'Ia oscuridad' no es agente, sino el ob to que provocó la sensación de 'susto' que exper 
Imentaron 'los niños'. 307 puede corresponder a sin la especificación del origen de la sensación, también puede corresponder a una forma re-

Los niños se asustaron (a sí mismos).

En 306 y 307, 'los niños' no manifiestan el caabje objivo sino el caso experientivo. En oraciones que corresponden a 304 y 305 , cuando lo que a manifiesta es el caso objetivo únicamente, si el alijeto está marcado como [+ animado], el espail no permite que la concordancia verbal sea con abjeto sino que la oración tenga la forma que malmente se asocia con oraciones activas pero fuerza activa. Es decir, en esta clase de oraciose destaca el proceso y no la acción.

Ejemplos de esto son:

Se acostó a los niños.

Se (les, los) derrotó a los enemigos.

En oraciones como 309 y 310 , el 'se' ocupa la ción que corresponde al clítico que se asocia el sujeto y manifiesta la forma de tercera perQue también manifieste el rasgo de singuse ve la conjugación singular del verbo. Al usado en esta función se le llama 'reemplae del sujeto'.

iv) El clítico reemplazante del sujeto puede aparecer en oraciones que expresan un concepto verbal genérico, que puede darse cuando el verbo es inherentemente de estado, o cuando un verbo de proceso, de acción o de acción-proceso tiene una flexión estativa y toda la predicación es genérica. En estos casos, también, la referencia del clítico es a un sustantivo indeterminado, o indefinido o impersonal, que tiene los rasgos de tercera persona $y$ de singular, pero no tiene forma.

Compárense las siquientes oraciones:

Init1. Se es bueno o se es malo.

3i12. Se necesita empleados.

\#il3. Se alquila casas.

* Se son buenos o se son malos.
315. * Se son lo que son.

Además de limitarse este uso de 'se' a sujetos de tercera persona del singular, la predicación tiene que ser genérica. Compárense las siguientes oraciones:

316. Se alquila casas.

317. Se alquilaba casas.

318. * Se alquiló casas.

319. * Se al quila esas casas.

320. *Cada semana se alquila casas.

321. Sólo se es suicida después de muerto.

322. Sólo se era suicida después de muerto.

323. * Sólo se fue suicida después de muerto.

324. El hitita fue peleador por naturaleza.

325. *Se fue peleador por naturaleza.

326. En la arena del foro romano, o se era peleador o se era hombre muerto.

El verbo 'alquilar' puede usarse en función activa o en función estativa. En 316 y 317, la flexión estativa está marcada con la forma imperfectiva del verbo seguida por la forma genérica del sustantivo (sin determinante). La predicación es, pues, genérica.

El uso del aspecto perfectivo en 318 indica la flexión activa del verbo, y su referencia es a un solo acontecimiento en el tiempo. En este caso no es posible darle una interpretación genérica a 'casas'. Para que la oración 318 sea correcta, el español exige que el verbo sea plural, y el sustantivo puede ir marcado con el determinante o sin él. En 319 el verbo está marcado con el imperfectivo, que podría indicar un estado, pero el uso del determinante específico le resta toda posible interpretación genérica al sustantivo. En 320 la inclusión de 'cada semana' indica la función iterativa de la forma imperfectiva del verbo. Puesto que esta función implica una iteración de acontecimientos únicos, tampoco es posible darle una interpretación genérica a la oración. 
Si bien 'alquilar' puede entrar en flexiones de estado o de acción, 'ser suicida' sólo puede representar un estado. Cualquier verbo de acción o de proceso puede usarse en función de estado, dado algún contexto apropiado, pero las oraciones 321 a 323 demuestran que la estatividad del verbo seguida de una construcción genérica no es suficiente por sí sola. La predicación no puede ser genérica si el verbo no está marcado con el aspecto imperfectivo y si no se excluye toda posibilidad de interpretación iterativa.

Las condiciones para este uso de 'se' como sustituto del sujeto son las siguientes:

a. el sujeto de la oración debe ser indefinido;

b. la flexión del verbo debe ser estativa;

c. la forma del verbo debe ser imperfectiva; y

ch. la predicación debe ser genérica.

Si falta una sola de estas condiciones, no puede usarse 'se' en esta función.

Otra condición parece ser que la referencia del clítico, aún cuando sea a una forma vacía, debe tener el rasgo [+ humano]. Algunos hablantes aceptan la oración

\section{Se ladra mucho en una perrera.}

En la verificación, no todos aceptaban la oración, y ninguno la oración:

\section{8. * Se cacarea mucho en un gallinero.}

Puede ser que las personas que aceptan 327 lo hacen porque en nuestra cultura los perros muchas veces muestran características humanas.

\section{Compárese}

\section{Se nada bien en una pecera.}

La única interpretación posible sería la de que se trate de un sujeto humano.

El comportamiento de este 'se' reemplazante del sujeto no tiene nada de particular: es el de un clítico.

330. * Se no necesita empleados.

Puesto que 'se' no es el sujeto, sino el clítico que le corresponde al sujeto, es inseparable del verbo y la manifestación tiene que ser:
331. No se necesita empleados.

El español no permite que dos clíticos con la misma forma aparezcan juntos, ni siquiera en la misma cláusula, y excluye oraciones como

332. * Se se arrepiente aquí.

333. * Se se puede bañar aquí.

334. *Se puede bañarse aquí.

\section{Compárense:}

335. ¿Me le comprás un helado a ese niño? 336. * ¿Me me comprás un helado a mí?

D. En derivaciones.

Como se indicó arriba, al hablar de procesos derivados de estados 0 de acciones-procesos, 'se' puede indicar la destopicalización total de cualquier argumento que potencialmente podría ser sujeto de una oración. Esta destopicalización siempre se da cuando el verbo puede implicar más argumentos de los que hay implícitos en una oración dada o, si fuera implícito, no puede manifestarse en la superficie. Si pudiera manifestarse, sería el sujeto de la oración. En estos casos, la concordancia del verbo tiene que ser con uno de los argumentos presentes, cosa que no podría suceder si el argumento que fal ta estuviera presente en la oración no pasiva. Algunos ejemplos son:

337. Yo me quebré ('Me' es una manifestación específica de 'se').

338. Se le vendieron los caballos al dueño de la finca.

\section{Estos caballos se venden solos.}

En estas oraciones hay potencialmente un agente, pero, al no haberlo explícitamente, no está implícito. La concordancia verbal es con el objeto, que, por lo tanto, desempeña la función de sujeto.

340. Se asustaron los niños (por causa del hombre o por causa de la oscuridad).

341. Los hombres se enteraron de la noticia. 
En estas oraciones el agente potencial no es imwilicito, y la concordancia es con el experientivo.

3 -2 Se llenaron los picheles.

343. Se descargaron los camiones.

Se poblaron las colonias.

De nuevo no se manifiesta el agente potencial, la concordancia es con un locativo.

345. Se necesitan dos lápices.

Se destopicaliza el experientivo y la concordana es con el objeto.

346. Se heredó una fortuna.
Se destopicaliza el benefactivo y la concordancia es con el objeto.

\section{CONCLUSION}

En un breve trabajo de esta naturaleza, apenas si se puede dar alguna idea del área de interés de la Gramática de casos como exponente de una de tantas teorías lingüísticas que hoy ocupan a las personas que están interesadas en dar explicaciones, $y$ no simples descripciones metalingü ísticas, de fenómenos lingü ísticos en general, y especificamente de fenómenos de alguna lengua en particular, como aquí se ha intentado hacer con el español. Si con la lectura de este trabajo se logra despertar el interés de un solo amante del idioma español, se habrá cumplido con el objetivo principal que motivó su preparación.

\section{BIBLIOGRAFIA}

Wid Frances. 1973. Semantic structures in Spanish: A proposal for instructional materials. Washington, D. C.: Georgetown University Press.

Bello, Andrés. 1847. Gramática de la lengua castellana. Quinta edición. Buenos Aires: Sopena Argentina.

Cook, Walter. 1972. A case grammar matrix. Poligrafiado.

1973. Covert case roles. Poligrafiado.

Chafe, Wallace L. 1970. Meaning and the structure of language. Chicago: The University of Chicago Press.

Chomsky, Noam. 1965. Aspectos de la teoría de la sintaxis. Madrid: Aguilar, 1970.
D'Introno, Francesco. 1979. Sintaxis transformacional del español. Madrid: Cátedra.

Fillmore, Charles. 1968. The case for case. En Universals in linguistic theory. Bach y Harms, editores. New York: Holt, Rinehart and Winston.

Gili y Gaya, Samuel. 1943. Curso superior de sintaxis española. Barcelona: Bibliograf, $12^{\mathrm{a}}$ edición, 1978.

Lakoff, George. Stative verbs and adjectives in English. Poligrafiado.

Rivera, María Luisa. 1977. Estudios de gramática generativa del español. Madrid: Cátedra. 